\title{
Effect of Nature of Coal on Carbothermal Reduction of Barites
}

\author{
JYOTSNA AGARWAL \\ Vel Tech University, Chennai, India. \\ *Corresponding author E-mail: drjyotsnaagrwal@ymail.com \\ http://dx.doi.org/10.13005/ojc/300337
}

(Received: August 01, 2014; Accepted: September 01, 2014)

\begin{abstract}
The paper reports the effect of nature of coal on the carbothermal reduction of barite by using different types of coal. Usually in industrial practices, the reductive operations are carried out by using any type of cheap and easily available coal, but the extent of reduction rarely exceeds 35$40 \%$. After admixing the steam coal in matrix, yields have been found to increase to the order of 51 to $53 \%$. The obtained results prove to be quite economical in industrial practices.
\end{abstract}

Key words:Carbothermal reduction, barite, coal, carbon monoxide, activation energy.

\section{INTRODUCTION}

Barite is one of the major non-metallic minerals for export, consisting of mainly barium sulphate. This indigenous mineral has the unique distinction of having high specific gravity, water insolubility, non-magnetic nature etc. Due to all these properties it finds extensive applications in the field of paint, rubber, oil well drilling mud ${ }^{1}$, coat of automobile finishes for smoothness, corrosion resistance etc. One of the outstanding uses of barite is its application as a starting material for the production of various barium compounds but its high insolubility in water, further limits its applications.

Several process have been suggested for converting barite to barium sulphide ${ }^{2-7}$ (water soluble) which is the key material for the production of different barium chemicals. Out of these the process of carbothermal reduction of barite is the most common and practiced method in barium industries. The author has noticed that in most industrial reductive operations the range of reduction is usually 35 to $40 \%$, while theoretically a pure sample of barite should yield barium sulphide to the extent of $70 \%$ or so. It is a serious loss of such an important mineral and great dent to the economy of nation.

Sensitized by it author performed a series of experiments on the carbothermal reduction of barite under anaerobic conditions in pit furnace at high temperature in order to increase the yield of barium sulphide. 
The present study is a follow up of experimental investigations with hard and steam coal in order to find out their effects on carbothermal reduction of barite under anaerobic conditions. The results show that by using steam coal for carbothermal reduction of barite, the yield of barium sulphide has been found to be almost double than with hard coal. At high temperature oxidation of steam coal with barite is very fast due to low activation energy and releases a good amount of carbon monoxide ${ }^{8-11}$ (main reducing agent). This makes the reduction process easier and faster too.

\section{MATERIALS AND METHODS}

follows:

The raw materials used for study are as

\section{Barites (barium sulphate)}

Barite is the basic raw material. It was of two shades, snow-white and pink. Chemical analysis of both samples has been given in Table 1.

Barites of both grades were pulverized separately. The powder was checked for reactive

Table 1: Chemical analysis (mass \%) of the used barite ore samples

\begin{tabular}{lccccccc}
\hline Shades of barite & $\mathrm{BaSO}_{4}$ & $\mathrm{SiO}_{2}$ & $\mathrm{Al}_{2} \mathrm{O}_{3}$ & $\mathrm{Fe}_{2} \mathrm{O}_{3}$ & $\mathrm{MgO}$ & $\mathrm{Na}_{2} \mathrm{O}$ & $\mathrm{K}_{2} \mathrm{O}$ \\
\hline \#Snow white & 98.41 & 0.53 & 0.09 & 0.25 & 0.10 & 0.07 & 0.03 \\
*Pink shade & 96.95 & 0.92 & 0.19 & 0.84 & 0.18 & 0.13 & 0.06 \\
\hline
\end{tabular}

\#Snow white [Bhagat ka bas origin, Rajgarh, Alwar, (Raj.)]

impurities like dolomite/limestone and sieved through standard sieves of mesh number 150 mesh $^{12}$.

\section{Coal (hard and steam coal)}

For the purpose of comparative studies two types of coal (hard and steam coal) had been chosen
*Pink shade [Jamrauli origin, Rajgarh, Alwar, (Raj.)]

arbitrarily. Hard coal is more crystalline in texture, while the other variety i.e. steam coal is usually less crystalline, more amorphous and rich in volatile matter. Both types of coal were procured from local market. Their chemical analysis has been given in Table 2.

Table 2: Chemical analysis (mass \%) of the used steam and hard coal

\begin{tabular}{lcccc}
\hline Type of coal & Moisture & Volatile matter & Ash & Fixed carbon \\
\hline \multirow{2}{*}{ Steam } & 3.7 & 9.3 & 27.3 & 59.7 \\
Hard & 1.0 & 2.0 & 32.5 & 64.5 \\
\hline
\end{tabular}

Both of these coal were used for carbothermal reduction as well as a source of high temperature in the pit furnace. For carbothermal reduction they were pulverized separately and graded through 80 mesh number standard sieves. After this they were mixed with the barites for their carbothermal reduction.

\section{Clay Pots}

Clay pots of $250 \mathrm{ml}$ were used for carbothermal reduction of barites.

\section{Chemical reagents}

Reagents required for the estimation are discussed below ${ }^{13}$.

\section{lodine solution $(0.1 \mathrm{~N})$}

It is prepared by dissolving $12.7 \mathrm{gm}$ of A.R iodine in the conc. solution of potassium iodide (20 gm of A.R potassium iodide in $30-40 \mathrm{ml}$ of distilled water). It is shaken in cold water until all iodine is dissolved. The solution is allowed to acquire room temperature. The volume is made up to one litre with distilled water and kept in a cool and dark place. 


\section{Sodium thiosulphate solution $(0.1 \mathrm{~N})$}

$25 \mathrm{gm}$ of A.R sodium thiosulphate is dissolved in boiled out distilled water. The solution is made up to one litre.

\section{Dilute hydrochloric acid (5N apporx.)}

$45 \mathrm{ml}$ of pure conc. hydrochloric acid is poured into $30 \mathrm{ml}$ of distilled water. The solution is made up to $100 \mathrm{ml}$ and was shaken to ensure thorough mixing.

\section{Indicator solution}

$0.01 \mathrm{gm}$ of mercuric iodide and $5 \mathrm{gm}$ of starch is triturated with $50 \mathrm{ml}$ of water in a mortar. The paste is poured into one litre of boiling water with constant stirring and boiled for 5 minutes. After cooling, the clear solution is decanted.

For the carbothermal reduction, trial heterogeneous mixture of powdered pink shaded barite was prepared by mixing it with steam and hard coal separately in 2:1 ratio (coal percentage was taken $50 \%$ by weight of barite). The trial heterogeneous mixture of white shaded barite was also prepared in the same way. Trial mixes so obtained were filled in clay pots of $250 \mathrm{ml}$. In the pit furnace (depth = one meter and diameter $=0.37 \mathrm{~m}$ ) both hard and soft coal (as a source of high temperature) and clay pots filled with the charge consisting of barites, steam and hard coal (in 2:1 ratio) are placed over the furnace gratings in alternating manner and the furnace was fired. After cooling of the furnace the reduced mass is obtained by breaking the clay pots carefully in the form of lumps. The entire process takes about 48 hours. Reduced crude lumps of barium sulphide are recrushed in the pulveriser. The black powder (BaS) so obtained is called black ash ${ }^{14,15}$. This powdered black ash is extracted with boiled water for making barium chemicals in subsequent steps. The amount of barium sulphide (formed from the given amount of barite) percentage in the reduced mass, is found out by the estimation of sulphide ion in accordance with the available Indian standards ${ }^{14}$.

\section{Estimation of sulphide}

Sulphide ion in the presence of hydrochloric acid reacts with iodine ions as follows:

$$
\begin{gathered}
\mathrm{S}^{-2}+\mathrm{I}_{2} \rightarrow \mathrm{S}+2 \mathrm{I}^{-} \\
\text {e.g. } 2 \mathrm{BaS}+\mathrm{I}_{2} \rightarrow 2 \mathrm{Bal}+2 \mathrm{~S}^{-}
\end{gathered}
$$

Hence $S^{-2}$ ion react with iodine in molar ratio. The latter was estimated conveniently iodimetrically ${ }^{16}$.

To estimate the percentage of sulphide ions in reduced black ash, known amount of finely powdered black ash is added into hot water and boiled for 4 to 5 minutes. After filtering, the residue was washed with hot water for say about $3-4$ times ${ }^{14}$. The filtrate was made up to the required volume.

From the above prepared solutions the sulphide ions were estimated in accordance with the available Indian standards ${ }^{14}$.

\section{RESULTS AND DISCUSSION}

3.

Observed results are summarized in Table

\section{Effect of steam and hard coal on carbothermal reduction of barites:}

The reductive action of steam and hard coal on pink and white variety of barites is shown in figure 1. It is clear from figure that by using steam coal, the extent of carbothermal reduction of barite increases effectively.

Table 3 summarises the effect of quality of coal on carbothermal anaerobic solid phase reduction of barites in the pit furnace. The obtained results show that the general impact of steam coal in the carbothermal reduction of barite increases the yield of barium sulphide.

Chemically the possible reactions involved in the clay pots at the temperatures of the pit furnace $\left(1200^{\circ} \pm 200^{\circ}\right)$ are as follows:

At high temperature when barite (barium sulphate) comes in contact with carbon (coal) it forms carbon dioxide gas which further reacts with unreacted carbon and gives off carbon monoxide gas (the main reducing agent) :

$$
\begin{aligned}
& \mathrm{BaSO}_{4}+2 \mathrm{C} \rightarrow \mathrm{BaS}+2 \mathrm{CO}_{2} \\
& 2 \mathrm{CO}_{2}+2 \mathrm{C} \rightarrow 4 \mathrm{CO}
\end{aligned}
$$


Table 3. Effect of steam and hard coal on carbothermal reduction of barite Matrix composition (w/w):
(a) Barite (150 mesh) - 2parts,
(b) Coal -
(i)Steam coal (80 mesh) - 1 part,
(ii) Hard coal (80 mesh) - 1 part,
(c) Colour of black ash - Blackish grey

\begin{tabular}{cccc}
\hline $\begin{array}{c}\text { S. } \\
\text { No }\end{array}$ & $\begin{array}{c}\text { Nature of } \\
\text { coal taken }\end{array}$ & $\begin{array}{c}\text { Nature of } \\
\text { barite taken }\end{array}$ & $\begin{array}{c}\text { Extent of reduction of barite } \\
\text { (in terms of \% of BaS in black ash) }\end{array}$ \\
\hline \multirow{2}{*}{ 1. } & Hard & \#Snow white & 24.0 \\
& & *Pink shade & 23.2 \\
& \multirow{2}{*}{ S. Steam } & \#Snow white & 52.5 \\
& & *Pink shade & 51.3 \\
\hline
\end{tabular}

This produced carbon monoxide gas diffuses back and reacts with unreacted barium sulphate, thus overall reaction for the anaerobic carbothermal reduction of barite with coal can be represented as follows:

$$
\begin{aligned}
& \mathrm{BaSO}_{4}+4 \mathrm{C} \rightarrow \mathrm{BaS}+4 \mathrm{CO} \\
& \mathrm{BaSO}_{4}+4 \mathrm{CO} \rightarrow \mathrm{BaS}+4 \mathrm{CO}_{2}
\end{aligned}
$$

This carbondioxide diffuses back into carbon to generate more carbon-monoxide:
The varying nature of carbothermal reduction under anaerobic conditions suggests the lack of availability of free oxygen, because the activation energy of hard coal is more than that of the steam coal in oxidative processes. Hence it is expected that the oxidation of hard coal should be more difficult when no free oxygen is available. Proposed reactions are as follows:

$$
\mathrm{C}_{\text {(hard coal) }}+1 / 2 \mathrm{O} \rightarrow \mathrm{CO}
$$

$$
\mathrm{CO}_{2}+\mathrm{C} \rightarrow 2 \mathrm{CO}
$$

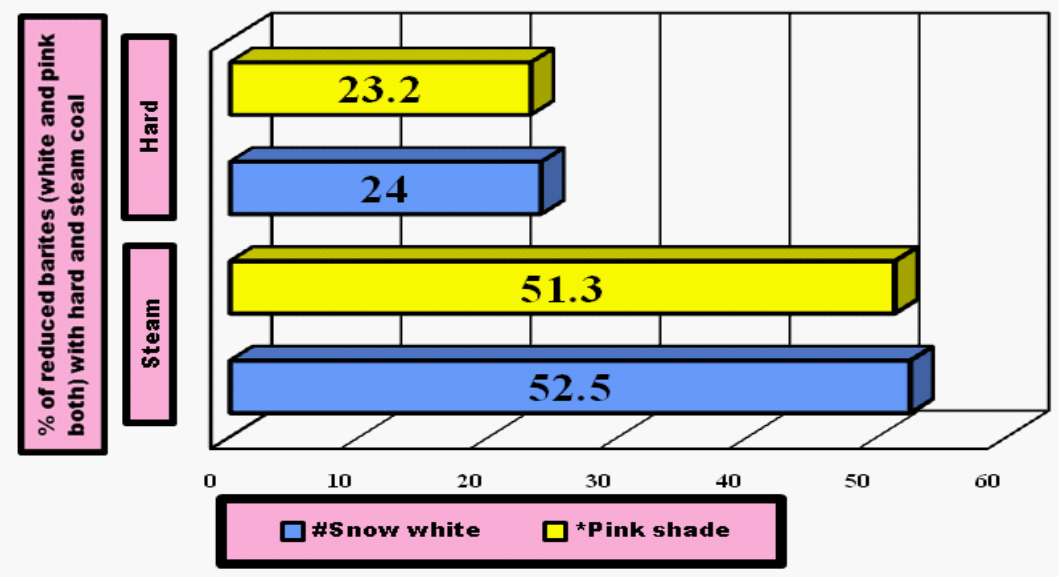

Fig. 1: Extent of reduction of white and pink barites with steam and hard coal 


$$
\begin{aligned}
& \mathrm{C}_{\text {(steam coal) }}+1 / 2 \mathrm{O}_{2} \rightarrow \mathrm{CO} \\
& \text { (More amount of } \mathrm{CO} \text { ) } \\
& \mathrm{CO} \quad+\frac{1}{2} \mathrm{O}_{2} \rightarrow \mathrm{CO}_{2} \\
& \mathrm{BaSO}_{4}+\mathrm{C}_{\text {(hard coal) }} \stackrel{\text { Sluggish }}{\rightarrow} \mathrm{BaS}+\mathrm{CO} \\
& \mathrm{BaSO}_{4}+\mathrm{C}_{\text {(soft coal) }} \underset{\text { (Good yield) }}{\mathrm{BaS}}+\mathrm{CO}
\end{aligned}
$$

Reactions (3), (4), (5), (7) and (10) are quite favourable for the carbothermal reduction of barites. It is clear from the experimental results of present investigations that in carbothermal reduction of barite, steam coal with low specific gravity and rich volatile carbon components gives far better results than normal hard coal (up to the experimental limits).

\section{CONCLUSIONS}

Hard and crystalline coal is not suitable for the carbothermal reduction of barite under anaerobic conditions.

Soft charcoal rich in volatile carbon is ideally suitable for the carbothermal reduction of barite under anaerobic conditions.

\section{REFERENCES}

1. Kresse, R.;Baudis, U,; Jäger, P.; Hermann, H. R.; Wagne, H.;Hans, J.W.;Wolf, U, Ullmann's Encyclopedia of Industrial Chemistry, WileyVCH, Weinheim, (2007).

2. Hargreaves, K. and Murray.D.M, Journal of Chemical Technology and Biotechnology, 1989, 45(4), 319-325.

3. Lozhkin,A.F.; Pashcenko,V.N.;Povar, F.V:J. Appl. Chem. USSR, 1974,47 (5), 1031-1034.

4. Jagtap,S.B.; Pande,A.R.; .Gokarn, A.N: Ind. Eng. Chem. Res.1990, 29, 795-799.

5. Pechkovski,V.V.; Ketov A.N., Zh. Prkl. Khim. 1960, 33,1719-1723.

6. Pelovski, Y.; Gruchavov I.; Dombalov.,J. ThermalAnal. 1987, 32, 1743-1745.

7. Kirk, Othmer, Encyclopaedia of Chemical Technology, Vol III.; John Wiley.New York, (1991).

8. Carbon black product, 2716053, (Phillips Petroleum Company), US, 1955.

9. Ingles, O.G.;Aust.,J. Appl. Sci., 1953,4(3),
451- 461.

10. Rosenquist E N., The Production of MonoVinyl Chloride, FIAT Final report 867.(Hobart Publishing Company, Washington DC), (1946).

11. Carbon monoxide.A bibliography with abstracts, Washington DC, DHEW publication, 1502 (US Govt. Printing Office, Washington DC), 1966.

12. Salem, A.; Tavakkoli, Y.O.;Mater. Res. Bull., 2009, 44,1489-1493.

13. IS: 1070 - Specification for Water, Distilled Quality (ISI,New Delhi), 1971.

14. IS: 5877- Specification for Barium Sulphide. Technical (Black ash) (ISI, New Delhi), 1971.

15. Barites A market survey MSI (Indian Bureau of Mines, Nagpur), 1988.

16. Arthur, V. I.; A text Book of quantitative Inorganic analysis, $3^{\text {rd }}$ Ed., (ELBS and LongmansGreen \& Co Ltd, London), 1962. 